\title{
Exploring Chinese Bicultural Students' College Adjustment Process
}

\author{
Guicheng “Ariel” Tan a," \\ ${ }^{a}$ New York University, United States \\ *Corresponding author: Email: arielgtan@ nyu.edu \\ Address: New York University, New York, New York, Unites States
}

\section{Introduction}

Chinese international students and immigrant students experience college adjustment differently from their peers and among each other. By inspecting the interaction between bicultural identity integration and the college adjustment experience, the present quantitative study explores ways in which biculturalism, acculturation stress, and social capitals influences and reflects the needs of different Chinese students. Research has used "Chinese internationals" as a generalized term for both international students and first-generation immigrants. Despite their shared ethnic background, Chinese international students and immigrant students are two unique student bodies with distinct needs.

Previous research illustrates that immigrant students have more family support, fewer employment barriers, and more desire to acculturate in the US compared to international students (Tsai, Ying and Lee 2000; Ye 2006). This comparison points out differences among Chinese internationals' personal, academic, and professional motivations during college, thus implying the different needs of these two groups. In terms of identity development, studies have found that Chinese immigrant students face potential identity crisis when navigating between two cultures and express an ambiguous concept of home and multilayered identities during acculturation (Kwan and Sodowsky 1997; Liu 2017). When considering current studies on Chinese students' college experiences (Ching, Renes, McMurrow, Simpson, and Anthony 2017), there is a lack of side-by-side comparisons between levels of cultural integration and college transition for this student population. This brings forth the question of how Chinese international and immigrant students adjust to college differently, and whether biculturalism plays a role throughout this process.

\section{Theoretical Framework}

Bicultural Identity Integration (BII) theory, a recently developed biculturalism framework, contains two independent psychological constructs: internally perceived cultural conflicts and externally perceived cultural distance (Benet-Martinez and Haritatos 2005). This theory explores personal experiences when navigating identity-related concepts through interviews with Chinese bicultural individuals who lived in both China and the US for at least five years. BII represents an intersectional effort that could be applicable when looking at the development of Chinese college students in the US. Because of the limited identity development frameworks for bicultural students in the current academia (Patton, Renn, Guido, and Quay 2016), this study hopes to examine Chinese international and immigrant student's college adjustment process using a bicultural integration framework.

Acculturative stress is included as a part of the study due to its important impact on bicultural individuals. For most Asian international students, acculturative stress can hinder their academic performance and social interactions with others (Han, Pistole and Caldwell 2015; Wei, Heppner, Mallen, Ku, Liao, and $\mathrm{Wu}$ 2007). In contrast, acculturative stress for Chinese immigrant youths is complicated by the navigation among cultural identities and family dynamic. A recent study challenged the unilateral perceptive of US immigration and identified Chinese immigrant youth's desire to transition between countries and identities (Liu 2017), which could amplify the frequency of acculturative stress 
experienced by Chinese immigrant students through constant cultural switching. Moreover, a study focused on Canadian Chinese immigrant families pointed out the spillover effects of parental acculturative stress which reduced positive parenting for Chinese immigrant youth (Miao, Costigan and MacDonald 2018). Since levels of cultural integration appear to be an acculturative variation for Chinese international and immigrant students, this study includes acculturative stress as a research component in examining biculturalism in college adjustment.

Within the realm of acculturation, social capitals persist as both challenging and mediating factors towards students' adjustments in the US. As people acculturate in a new environment, the type of social support received from social capitals can reduce stress and provide a coping mechanism for individuals (Wills and Shinar 2000). For Chinese international students, perceived social network mediates their acculturative stress levels (Lee, Koeske and Sales 2004; Ye 2006). It is believed that an increase in one's social network can lead to positive social interactions, which buffers acculturative stress during the adjustment period. Because social capitals play an important role in one's adjustment to a new culture, this study includes social capital as a part of the research question to better understand the relationship between bicultural integration and college adjustment.

\section{Method}

Based on Benet-Martínez's BII's framework, the extent to which an individual perceives two cultures as complimentary or conflicting (Benet-Martinez and Haritatos 2005), this study hypothesizes the following: 1) Chinese students with high BII scores will score higher on their college adjustment scale compare to Chinese students with low BII scores, 2) BII scores will mediate the levels in which social capital and acculturation influence college adjustment, and 3) Chinese students with high BII scores will have a higher level of social capital and a lower level of acculturative stress compare to Chinese students with low BII scores.
The target population for this study is students identified as Chinese international students or firstgeneration immigrant students who have lived at least for 5 years in both China and the US (Benet-Martinez and Haritatos 2005). Participants will complete a survey composed of the following questionnaires and existing Likert scales: Bicultural Identity Integration Scale (BenetMartinez and Haritatos 2005), Social Capital Scale (Ellison, Steinfield, and Lampe 2008), Riverside Acculturation Stress Inventory (Benet-Martinez and Haritatos 2005), and College Adjustment Questionnaire (O’Donnell, Shirley, Park, Nolen, Gibbons, and Rosén 2018). This study includes these scales to measure the following variables respectively: level of BII, acculturation stress, social capital, and college adjustment.

\section{Results and Implications}

The study is currently in the data collection phase. It seeks to answer questions about ways in which bicultural identity influences Chinese students' college adjustments and how does the level of bicultural identity integration mediate acculturative stress and social capital for their college adjustments.

From a practitioner perspective, understanding how biculturalism influences students' adjustments can yield into programs and services improvements. For instance, many international student centers only provide administrative and transactional services such as visa processing for international students or study abroad advising for domestic students (Open Doors ${ }^{\circledR} 2016$ Report on International Educational Exchange 2016). If this study reveals the need for identity exploration and campus climate navigation, international offices can better identify opportunities to collaborate with multicultural affairs and provide support for immigrant students.

In multicultural initiatives, many practices follow an outdated Asian American Identity Development Model that did not capture the comprehensive Asian Americans narratives, let alone bicultural voices (Kim 1981). This study can provide helpful reflections starting with Chinese students with international backgrounds (immigrants or international students), 
adding academic insights and improvements for the Asian racial and ethnic identity development.

Lastly, this study sheds lights on the lack of awareness for bicultural students. Findings from this study can raise concerns about policy initiatives such as including "bicultural" as student demographic descriptions in campus climate surveys to capture their perspectives. Institutions can use reflections on how bicultural students adjust to colleges to re-evaluate and address their previous assumptions about student groups.

\section{References}

Benet-Martinez, Veronica, and Jana Haritatos. 2005. "Bicultural Identity Integration (BII): Components and Psychosocial Antecedents." Journal of Personality 73 (4): 1015-50.

https://doi.org/10.1111/j.1467-6494.2005.00337.x.

Ellison, Nicole B., Charles Steinfield, and Cliff Lampe. 2007. "The Benefits of Facebook 'Friends:' Social Capital and College Students' Use of Online Social Network Sites." Journal of Computer-Mediated Communication 12 (4): 1143-68.

https://doi.org/10.1111/j.1083-6101.2007.00367.x.

Han, Suejung, M. Carole Pistole, and Jarred M. Caldwell. 2017. "Acculturative Stress, Parental and Professor Attachment, and College Adjustment in Asian International Students." Journal of Multicultural Counseling and Development 45 (2): 111-26. https://doi.org/10.1002/jmcd.12068.

Institute for International Education. 2016. "Open Doors ${ }^{\circledR} 2016$ Report on International Educational Exchange.” Washington, D.C.: National Press Club. Kim, Jean. 1981. "Processes of Asian American Identity Development: A Study of Japanese American Women's Perceptions of Their Struggle to Achieve Positive Identities as Americans of Asian Ancestry." Dissertation. University of Massachusetts Amherst.

Kwan, Kwong-Liem Karl, and Gargi Roysircar Sodowsky. 1997. "Internal and External Ethnic Identity and Their Correlates: A Study of Chinese American Immigrants." Journal of Multicultural
Counseling and Development 25 (1): 51-67. https://doi.org/10.1002/j.2161-

1912.1997.tb00315.x.

Liu, Xiangyan. 2017. "Redefining "Immigrants" Through Diaspora: Educational Experience of 1.5Generation Chinese Youth in Cupertino." Diaspora, Indigenous, and Minority Education 11 (4): 177-89. doi:10.1080/15595692.2016.1264384.

Miao, Sheena W., Catherine L. Costigan, and Stuart W. S. Macdonald. 2018. "Spillover of Stress to Chinese Canadian Immigrants' Parenting: Impact of Acculturation and Parent-child Stressors." Asian American Journal of Psychology 9 (3): 190-99. doi:10.1037/aap0000105.

O’Donnell, Maeve B., Lauren A. Shirley, Stacey S. Park, Julian P. Nolen, Alyssa M. Gibbons, and Lee A. Rosén. 2018. "The College Adjustment Questionnaire: A Measure of Students' Educational, Relational, and Psychological Adjustment to the College Environment." Journal of College Student Development 59 (1): 116-21.

https://doi.org/10.1353/csd.2018.0009.

Patton, Lori D., Kristen A. Renn, Florence M. Guido, and Quay. 2016. Student Development in College: Theory, Research, and Practice, 3rd Edition. John Wiley \& Sons.

Sodowsky, Gargi Roysircar, and Edward Wai Ming Lai. 1997. "Asian Immigrant Variables and Structural Models of Cross-Cultural Distress." In Immigration and the Family: Research and Policy on U.S. Immigrants, 1st ed., edited by Alan Booth, Ann C. Crouter, and Nancy Landale, 211-34. Penn State University Family Issues Symposia Series. Hillsdale, NJ: Routledge.

Tsai, Jeanne L, Yu-Wen Ying, and Peter Allen Lee. 2001. 'The Meaning of 'Being Chinese' and 'Being American' Variation among Chinese American Young Adults. Journal of Cross-Cultural Psychology, 31(3), 302-332." Cultural Diversity and Ethnic Minority Psychology 7 (3): 284-97.

Wei, Meifen, P. Paul Heppner, Michael J. Mallen, Tsun-Yao Ku, Kelly Yu-Hsin Liao, and Tsui-Feng Wu. 2007. "Acculturative Stress, Perfectionism, Years in the United States, and Depression among 
Chinese International Students." Journal of Counseling Psychology 54 (4): 385-94.

https://doi.org/10.1037/0022-0167.54.4.385.

Wills, Thomas A., and Ori Shinar. 2000. "Measuring Perceived and Received Social Support." Social Support Measurement and Intervention, 86-135. https://doi.org/10.1093/med:psych/9780195126709. 003.0004 .

Ye, Jiali. 2006. "An Examination of Acculturative Stress, Interpersonal Social Support, and Use of
Online Ethnic Social Groups among Chinese International Students." Howard Journal of Communications 17 (1): 1-20. https://doi.org/10.1080/10646170500487764.

Yuerong, Ching, L. Renes Susan, Mcmurrow Samantha, Simpson Joni, and T. Strange Anthony. 2017. "Challenges Facing Chinese International Students Studying in the United States." Educational Research and Reviews 2 (8): 473-82. https://doi.org/10.5897/err2016.3106. 